\title{
O TEXTO ELETRÔNICO HIPERTEXTUALIZADO: A MÁQUINA, O AUTOR E O LEITOR
}

\author{
Emanoel Cesar Pires de Assis \\ Doutorando em Letras \\ Universidade Federal de Santa Catarina -UFSC \\ lordemanoel@gmail.com \\ Saulo Cunha de Serpa Brandão \\ Doutor em Letras \\ Universidade Federal do Piauí - UFPI \\ brandaosaulo@yahoo.com
}

O leitor de uma narrativa tradicional está temporalmente marcado por uma estrutura de começo, meio e fim. Já o leitor interativo-imersivo da narrativa eletrônica experimenta temporalidades narrativas múltiplas; diríamos mais, além de múltiplas elas podem ser análogas e/ou contraditórias, uma vez que a estrutura descentralizada da leitura hipertextual desloca espaço e tempo, dando ao leitor a experiência de uma leitura topográfica; ou seja, visual e estruturalmente concebida como se fosse a leitura de um mapa, onde não há um ponto inicial estabelecido, mas, sim, vários caminhos que podem ser seguidos. Ao deslocar o tempo, a leitura hipertextual torna-se um presente constante e contínuo. Assim: “O leitor eletrônico lê e não conclui sua leitura no tempo. O que faz é experimentar constantemente, em releituras sucessivas, possibilidades narrativas alternativas em uma vasta dimensão espacial e em um eterno presente" (BELLEI, 2002, p. 122).

Se as novas práticas de leitura fizeram surgir um novo tipo de leitor, "o leitor das telas eletrônicas" (SANTAELLA, 2004, p. 18), houve também alguma mudança no que diz respeito ao autor? Se as narrativas digitais permitem uma tênue divisão entre leitura e escrita, de que forma ainda poderíamos falar sobre uma autoria unilateral do texto?

A noção de autoria, segundo Roland Barthes (1968) e Pedro Barbosa (1996a), é recente. Para o primeiro, em A Morte do Autor,

O autor é uma personagem moderna, produzida sem dúvida pela nossa sociedade, na medida em que, ao terminar a Idade Média, com o empirismo inglês, o racionalismo francês e a fé pessoal da Reforma, ela descobriu o prestígio pessoal do indivíduo, ou como se diz mais nobremente, da "pessoa humana" (BARTHES, 1968). 
Já para o português estudioso da ciberliteratura:

É, na verdade, relativamente recente a incrustação da autoria como parte indissociável da obra, pois tempos houve em que as obras eram anónimas e o anonimato fazia parte da essência delas como hoje faz parte o serem assinadas individual ou coletivamente. [...] Os antigos preocupavam-se pouco com a assinatura das obras e muitos livros medievais ou de origem popular chegaram até nós anónimos, sendo, até, de admitir um anonimato colectivo em muitos casos (BARBOSA, 1996a, p. 112).

Assim, se na antiguidade, obra e autor não necessariamente precisavam estar atrelados e, mais recentemente, o papel deste para desvendar os segredos do texto também vem sendo questionado, qual seria a função do autor no texto hipertextual? Antes de termos a resposta para mais essa pergunta, façamos uma retrospectiva da crítica literária e alguns de seus focos.

Se traçarmos uma linha e evidenciarmos o foco da crítica literária ao longo dos anos, perceberemos que tal foco modificou-se nas diferentes correntes literárias. Em um primeiro momento, com a abordagem humanista da crítica, tinha-se como ênfase a pessoa do autor. Procurava-se compreender um texto a partir da questão: O que quis dizer o autor? Essa busca pela intencionalidade do autor, apesar de vários movimentos literários terem se colocado contra tal posição, reinou por muito tempo e era o ponto central de alguns manuais literários.

Uma vez alcançada a intenção do autor, tinha-se interpretado o texto e descoberto o seu "sentido". Sentido, no singular mesmo, pois se o texto era a resposta do autor ao mundo, esse possuía o sentido que o autor lhe atribuiu durante a sua feitura.

A respeito desta prática, Antonie Compagnon (2010, p. 50), em referência ao artigo de Barthes, expõe: “'A explicação da obra é sempre procurada do lado de quem a produziu', como se, de uma maneira ou de outra, a obra fosse uma confissão, não podendo representar outra coisa que não a confidência". Nesse prisma, a obra literária se fecharia ao mundo intencional do autor, não sendo possível associá-la a interpretações que não fossem as pensadas pelo autor.

Posterior ao foco dado ao autor, temos o foco dado ao texto e suas características imanentes. Nessa perspectiva, podemos citar o Formalismo Russo, o Estruturalismo e o New Criticism americano. Essas correntes literárias viam o texto como repositório para todas as questões que pudessem ser levantadas a respeito de sua interpretação e significação, não levando em consideração os aspectos contextuais, sociais ou biográficos.

Tinha-se uma abordagem linguística da literatura (Formalismo Russo), científica e técnica (New Criticism) e estrutural (Estruturalismo). O que todos esses movimentos tinham em comum era a não aceitação de que texto e autor fundam uma relação indissociável, em que o texto sempre responde às expectativas do seu autor e a impossibilidade de se efetuar interpretações além das pensadas por ele. 
Mais recentemente, as postulações teóricas da Estética da Recepção dão como foco dos estudos literários o leitor e o seu atuante papel na constituição dos sentidos do texto. Dessa forma, se condensarmos essa linha cronológica, veremos que os focos dos estudos literários repousaram inicialmente no autor, depois no texto, para em seguida recaírem sobre o leitor.

Feito esse breve levantamento histórico sobre os focos de alguns movimentos literários e percebendo a posição do autor neles, voltemos a verificar as particularidades da autoria nas narrativas hipertextuais em meio digital.

Teria o autor também "morrido" na literatura em ambiente digital? Não é esse o ponto que queremos defender, tampouco aceitar o seu caráter dominante no que diz respeito à significação da obra. Acreditamos que autor e leitor fundam uma íntima relação no que concerne às narrativas em ambiente eletrônico, principalmente as hipertextuais e interativas. O motivo de nossa afirmação será demonstrado nas linhas que se seguirão.

Para Barthes (1968),

Apesar de o império do Autor ser ainda muito poderoso (a nova crítica não fez muitas vezes senão consolidá-lo), é evidente que certos escritores já há muito tempo que tentaram abalá-lo. Em França, Mallarmé, sem dúvida o primeiro, viu e previu em toda a sua amplitude a necessidade de pôr a própria linguagem no lugar daquele que até então se supunha ser o seu proprietário; para ele, como para nós, é a linguagem que fala, não é o autor; escrever é, através de uma impessoalidade prévia - impossível de alguma vez ser confundida com a objetividade castradora do romancista realista -, atingir aquele ponto em que só a linguagem atua, "performa", e não "eu": toda a poética de Mallarmé consiste em suprimir o autor em proveito da escrita.

A leitura hipertextual, em si mesma, reprime uma consolidação autoral, na medida em que é feita de tessituras múltiplas e evoca uma intertextualidade latente, pondo em nível superior ao do autor a própria linguagem e a forma como ela se apresenta. As múltiplas facetas do hipertexto possibilitam reunir autores vários em uma mesma obra, impossibilitando definir um caráter autoral individual, uma vez que o que teríamos seria um texto bricolado, misto e em constante mutação devido ao caráter transmutável que o ambiente eletrônico confere ao texto.

Teríamos então um texto sem origem? Destituído de uma autoria? Para Compagnon (2010), que, vale ressaltar, não faz postulações sobre a autoria em narrativas hipertextuais, mas que pode ter suas proposições tomadas de empréstimo:

Sem origem, "o texto é um tecido de citações": a noção de intertextualidade se infere, também ela, da morte do autor. Quanto à explicação, ela desaparece com o autor, pois que não há sentido único, original, no princípio, no fundo do texto. Enfim, último elo do novo sistema que se deduz inteiramente da morte do autor: o leitor, e não o autor, é o lugar onde a unidade do texto se produz, no seu destino, não na sua origem; mas 
esse leitor não é mais pessoal que o autor recentemente demolido, e ele se identifica também a uma função (COMPAGNON, 2010, p. 50-51).

Se é no destino, o leitor, que a unidade do texto se produz e não na sua origem, o autor, na obra hipertextual essa afirmativa ganha um redimensionamento na medida em que requer do leitor uma posição ativa, na maioria das vezes, para que os seus interstícios possam ser perscrutados/ativados. Compagnon serviu-se da seguinte citação de Barthes (1968):

Assim se revela o ser total da escrita: um texto é feito de escritas múltiplas, saídas de várias culturas e que entram umas com as outras em diálogo, em paródia, em contestação; mas há um lugar em que essa multiplicidade se reúne, e esse lugar não é o autor, como se tem dito até aqui, é o leitor: o leitor é o espaço exato em que se inscrevem, sem que nenhuma se perca, todas as citações de que uma escrita é feita; a unidade de um texto não está na sua origem, mas no seu destino, mas este destino já não pode ser pessoal: o leitor é um homem sem história, sem biografia, sem psicologia; é apenas esse alguém que tem reunidos num mesmo campo todos os traços que constituem o escrito.

Ambos os autores referem-se a uma escrita múltipla, saída de várias culturas e em constante diálogo, não seria essa escrita a obra hipertextual? As características erigidas pelos autores são perfeitamente atribuídas às especificações da leitura de narrativas hipertextuais.

Landow (2006), assim como os autores supracitados, mas falando especificamente das obras hipertextuais, acredita que é no leitor onde as significações textuais repousam. Para o teórico americano, o hipertexto força uma descentralização do sujeito-autor, abrindo um espaço navegacional que vai ganhando sentido a partir do povoamento que o leitor faz das ilhas informacionais, as lexias ${ }^{1}$. Para ele,

As readers move through a web or network of texts, they continually shift the center and hence the focus or organizing principle of their investigation and experience. Hypertext, in other words, provides an infinitely recenterable system whose provisional point of focus depends on the reader, who becomes a truly active reader in yet another sense. One of the fundamental characteristics of hypertext is that it is composed of bodies of linked texts that have no primary axis of organization. In other words, the metatext or document set the entity that describes what in print technology is the book, work, or single text has no center. Although this absence of a center can create problems for the reader and the writer, it also means that anyone who uses hypertext makes his or her own interests the de facto organizing principle (or center) for the investigation at the moment. One experiences hypertext as an infinitely decenterable and recenterable system, in part because hypertext transforms any document that has more than one link into a transient center, a partial sitemap that one can employ to orient oneself and to decide where to go next (LANDOW, 2006, p. 56-57).

\footnotetext{
${ }^{1} \mathrm{O}$ conceito de lexia foi proposto por Barthes e é tomado de empréstimo pelo teórico norte-americano.
} 
Texto e autor são descentralizados, na medida em que sofrem fragmentações e aglutinações de textos diversos e autores outros. Resta ao leitor, centralizador da narrativa, a partir da leitura, recentralizar o texto a sua forma, sendo que sempre uma nova leitura é uma nova descentralização que sofre uma recentralização.

Assim, o que propomos é que há uma interligação entre autor e leitor, na medida em que não podemos afirmar uma não existência autoral, uma vez que a leitura hipertextual realizada - mesmo que possa ser realizada de forma não idealizada pelo autor - sempre segue pré-requisitos elaborados por ele. Para Barbosa (1996a),

A função do autor será a de estruturar o mais objetivamente possível a criação literária, e o leitor deverá encarar o texto como um objeto estético em certo grau independente do seu autor: o texto surge em primeiro plano, como se fosse ele mesmo - o texto - fonte originária de informação (p. 113).

O leitor, que para nós atua como coautor da narrativa última, fruto da leitura, tem a possibilidade de percorrer caminhos múltiplos ou nenhum caminho. Continuar realizando a leitura sem seguir nenhum link ou comando que o texto possa apresentar, mas que no fim, sempre continuará sendo um texto idealizado pelo seu autor. Fragmentado, desfacelado, sim, mas sempre proveniente de uma ideia ou conjunto de ideias que possuem uma origem.

Pode parecer, neste momento, que estejamos voltando no tempo e reapropiando o autor ao seu lugar de foco, engana-se o leitor. O que desejamos deixar claro é que é a partir de uma ligação entre autor, leitor e obra que a narrativa hipertextual se faz viva, multifacetada e mutável; que o hipertexto em ambiente eletrônico pode apresentar milhares de autores, mas nunca autor nenhum.

Desprover um texto de sua autoria seria o mesmo que acreditar que o texto criou-se sozinho, como um passe de mágica ou um feitiço conjurado nos caldeirões informacionais-magnéticos do computador. Alguns poderiam situar-se contra nossa afirmação e levantar a bandeira dos textos “criados" pelo computador, ${ }^{2}$ mas até que ponto a máquina exerceu um papel de autoria? Sem que se introduza nos discos rígidos do computador, informações prévias que possibilitem à máquina, através de, dentre outros processos, o da permutação lexical, realizar suas criações, poder-se-ia, ao fim, encontrar essas criações?

O português Pedro Barbosa nos dá vários exemplos de obras criadas com a ajuda do computador - é preferível para nós utilizar esses termos. Vejamos um destes exemplos para que possamos deixar mais claro nosso ponto de vista.

\section{Matriz:}

\footnotetext{
${ }^{2}$ Extenso estudo sobre a criação literária pode ser encontrado na obra de Pedro Barbosa A Ciberliteratura (1996).
} 
ERA UMA VEZ UMA JANELA. PENSOU IR BRINCAR COM AS MENINAS LÁ DA RUA E ATIROU-SE DA JANELA ABAIXO. O RESULTADO FOI PARTIR OS VIDROS TODOS E UMA DAS MENINAS DISSE: - TEVE MUITA SORTE EM NÃO ENTERRAR NENHUM VIDRO PELOS OLHOS DENTRO.

(“Sorte”, de Mário Castrim)

Assim, em princípio, temos um texto matriz que serve de modelo para que o programa computacional gere outros textos. Transcreveremos aqui 3 dos 11 textos gerados pelo software.

1

ERA UMA VEZ UM ASTRONAUTA. PENSOU IR BRINCAR COM AS MENINAS LÁ DA RUA E ATIROU-SE DO OVNI ABAIXO. O RESULTADO FOI AVARIAR AS MEMÓRIAS TODAS E UM FANTOCHE ATÉ DISSE: - TEVE MUITA SORTE EM NÃO ENFIAR NENHUM CURTOCIRCUITO POR AS ORELHAS ADENTRO.

2

ERA UMA VEZ UM VENUSINO. PENSOU IR BRINCAR COM OS HABITANTES DA TERRA E ATIROU-SE DA JANELA ABAIXO. O RESULTADO FOI PARTIR AS ANTENAS TODAS E UM POLÍTICO ATÉ DISSE: - TEVE MUITA SORTE EM NÃO ENTERRAR NENHUMA ANTENA POR OS MIOLOS DENTRO.

ERA UMA VEZ UM COMPUTADOR. PENSOU IR BRINCAR COM AS ALUNAS DA FACULDADE E ATIROU-SE DA LITERATURA ABAIXO. O RESULTADO FOI AVARIAR AS MEMÓRIAS TODAS E UMA DAS ALUNAS ATÉ DISSE: - TEVE MUITA SORTE EM NÃO ENFIAR NENHUM VIDRO POR OS OLHOS DENTRO.

Como se pode perceber, a partir do texto matriz, o software vai fazendo transformações de nível lexical e, assim, construindo outros textos. Custa-nos acreditar que sem o input (o texto matriz), idealizado por um autor individual e humano, a máquina fosse capaz de criar as outras versões. Com isso, se podemos falar em coautoria entre leitor e autor, acreditamos que o mesmo pode ser verificado entre máquina e autor.

Não podemos esquecer que, para a feitura dos textos, o computador utilizou dados já anteriormente armazenados e de um programa capaz de distinguir verbos e substantivos ou outras classes gramaticais. O que não quer dizer que a máquina estava consciente das permutações lexicais que ia realizando.

Barbosa (1996a), que defende um caráter se não autoral, pelo menos criativo do computador, faz a seguinte indagação: 
Quando um computador desenvolve e actualiza as possibilidades combinatórias, estruturais ou outras, deixadas em aberto por um determinado algoritmo potencial (como é aliás o caso dos algoritmos combinatórios), não poderemos afirmar que a máquina cria ou, pelo menos, actualiza algo que à partida não existia? (p. 35, grifo do autor).

Certamente, a máquina exerceu papel importante na criação que anteriormente não existia, mas, para nós, é preferível falar em um aspecto criativo do computador; na realidade dos programas computacionais desenvolvidos, assim como tudo o que há no computador, pela inteligência e criatividade humana. Vejamos a seguinte citação de Barbosa (1996a):

Acresce que, do outro lado do processo, é ainda um ser humano quem se oferece como destinatário terminal do sentido das mensagens estruturadas por computador. Por conseguinte pouco importa que as manipulações que a máquina faz dos símbolos formais sejam para ela destituídas de significado: os símbolos, no interior da máquina, não possuem propriedades simbólicas - eles só possuem uma sintaxe, não uma semântica. A intencionalidade e a significação do que os computadores parecem produzir apenas está na mente daqueles que elaboram o programa (dos que fornecem o input) ou então daqueles que interpretam os resultados (dos que recebem o output) (p. 36).

Voltamos então ao leitor e ao seu primordial papel para a feitura do texto em ambiente eletrônico. Para Bellei (2002),

A estrutura do hipertexto, ao enfatizar a conectividade, altera a situação e o comportamento do leitor e do autor característicos do livro impresso, no qual o autor tende a controlar o roteiro de leitura do leitor. Este parte de um índice linearmente organizado e percorre capítulos até chegar à página final. No hipertexto, perde-se, pelo menos em parte, a autoridade do autor como roteirista autoritário, e o leitor deve assumir uma certa responsabilidade (e um certo risco) para escolher alguns dos roteiros previamente estabelecidos e ignorar outros [...] (p. 47).

É assumindo um papel de roteirista que o leitor, coautor do texto, cria, a partir de sua leitura pessoal, uma obra que nunca é a mesma - a não ser que se intente percorrer sempre os mesmos passos.

Não podemos afirmar que é somente no hipertexto eletrônico que o leitor atua como roteirista do percurso que deseja efetuar. Consideremos a leitura da Bíblia, quase nunca lida de forma linear. O leitor sempre salta de um livro bíblico a outro, procurando passagens que retomem a temática ou simplesmente lendo de forma estrelada. O que distingue o roteirista hipertextual daquele de leitura em suporte impresso é a própria natureza conectora do hipertexto eletrônico: plástica, elástica e cambiável de forma não possível no documento impresso. 
Assim, para nós, fica evidente o papel de coautoria que o leitor exerce na leitura hipertextual. Traçando caminhos próprios e construindo narrativas novas, o leitor vai criando a obra a seu modo, obedecendo aos comandos autorais ou criando os seus próprios.

Além da noção de coautoria aplicada ao leitor, há quem o qualifique também de "escrileitor" (wreader, laucteur). Para Barbosa (1996b),

O circuito comunicacional da literatura encontra-se assim alterado, tanto do lado da criação como do lado da recepção. $O$ acto de leitura, enfim, pode tornar-se interactivo, envolvendo a participação do leitor na co-criação do texto final mediante um processo simultâneo de escrita-leitura: a escrileitura.

As características do coautor e do escrileitor são basicamente as mesmas, ambas as denominações veem o leitor como ativo produtor e criador de significados. Assim, “[...] o leitor participa do processo criativo num verdadeiro acto de co-criação: daí nascerá o 'escrileitor', aquele que pratica a leitura pela escrita e a escrita pela leitura numa nova simbiose interactiva" (BARBOSA, 1996b).

É o produto da simbiose entre leitura, escrita e máquina: a escrileitura, que nos incentiva a questionar o conceito de texto, surgido não mais como uma obra comunicacional, intersubjetiva na qual o autor faz uma ponte de sentidos com o seu leitor (BARBOSA, 1996b). O texto agora deve ser visto como processo, estrutura geradora de sentidos e em constante movimento, aberto, flexível e capaz de se fragmentar para em seguida se reconstruir. Uma tarefa repetitiva, porém semanticamente sempre renovada.

Se o que colocamos é verdadeiro, "então onde está o texto, quando a sua forma não cessa de se metamorfosear?” Questiona Philippe Bootz (apud BARBOSA, 1996b). Para responder à indagação de Bootz, voltemos ao início do texto, onde afirmamos que a leitura hipertextual desloca espaço e tempo e que o leitor experimenta constantemente possibilidades narrativas alternativas em uma vasta dimensão espacial e em um eterno presente. Assim, o texto está em um presente perpétuo, num agora que se faz e refaz sempre que o texto é lido. Infinitizado tanto no campo da criação quanto da recepção.

\section{REFERÊNCIAS}

BARBOSA, Pedro. A Ciberliteratura: criação literária e computador. Lisboa: Cosmos, 1996a.

Ângulos e virtualidades do texto virtual. 1996b. Disponível em: http://www.pedrobarbosa.net. Acesso em 15 de novembro de 2010. 
BARTHES, Roland. A Morte do Autor. 1968. Disponível em: http://www.artesplasticas.art.br/guignard/disciplinas/critica_1/A_morte_do_autor_barthes.pdf. Acesso em 15 de novembro de 2010.

BELLEI, Sérgio Luiz Prado. O livro, a literatura e o computador. São Paulo: Editora UFSC, 2002.

COMPAGNON, Antoine. O Demônio da Teoria: literatura e senso comum. Tradução de Cleonice Paes Barreto Mourão, Consuelo Fortes Santiago. 2. ed. Belo Horizonte: Editora UFMG, 2010.

LANDOW, George P. Hypertext 3.0: critical theory and new media in an area of globalization. Baltimore: John Hopkins University Press, 2006. 